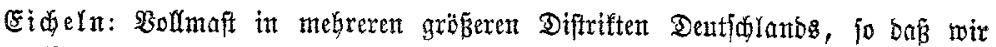

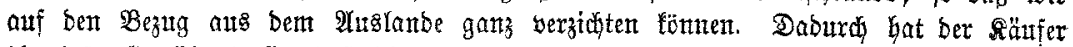
bie befte (Semäly bafitr, Daß fetute fremben, für unjere Rulturen atdit geeignete Sorten (ipeziell Berretcheln) vorfomment.

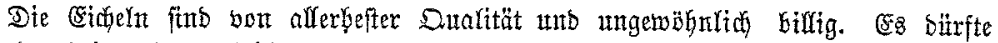

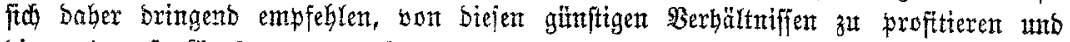

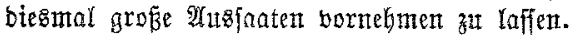

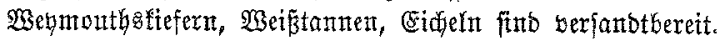

B̂t Ernte ans mantuen Begentsen beridatet wirb, if wohl anzunebnten, baj fpäter bod etwos geliefert werben tann.

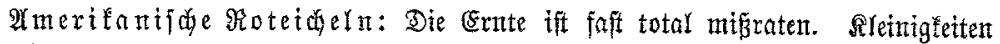

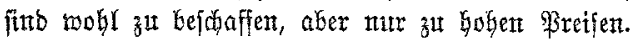

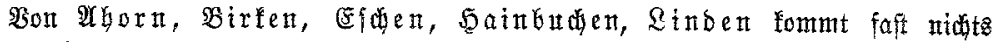

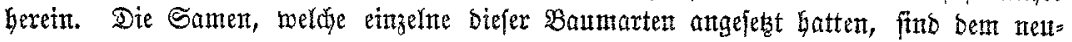
liden Sturme zum Spfer gefalfen.

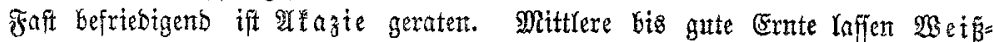

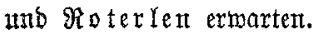

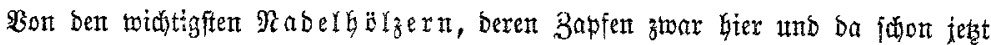

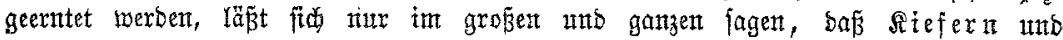

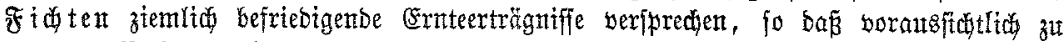

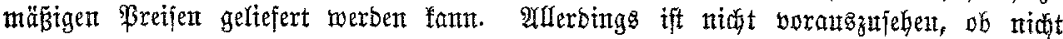

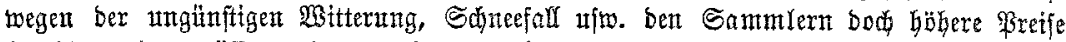
bezahlt toerben milfifen, als man ferte annimmt.

gärdinzapfen idjetnt es bagegen wentig zat geben.

Bit $x$ beln it $j\{:$ : gentifgettber Ertrag.

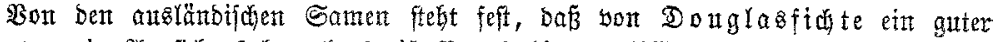

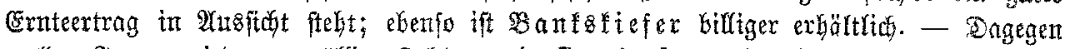
melbet Sapan weserm yöllige Feflernte in Larix leptolepis.

Darmftabt, im Sttober 1903.

\title{
Gohe Bublenholzpreife.
}

Die Beteitignng bet eitrer an 16. Noventfer 1903 eröffneten Submiffion bei bent

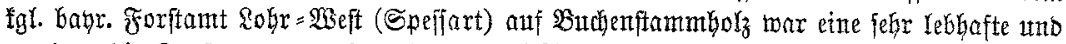

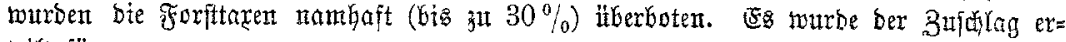
teilt fütr

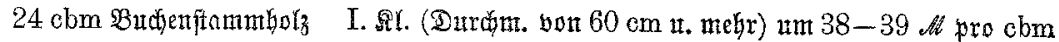

60 ,

175 "

350

175

265,

740 "Butuenjounelfentyolz

II. "( "

III. $" ; "$

IV. "i "

V. " : "

VI.

$$
\begin{aligned}
& 50-59 \mathrm{~cm}) \text { um } 31-33 \text {, } \\
& 40-49 \text { ") " } 20-21,70 \text {, } \\
& 30-39 \text { ") " } 15,80-17,18 \text {. } \\
& 25-29 \text { ") " } 11,27-13,68 \text { " } " 9,47-10,37 \text { " }
\end{aligned}
$$$$
9,47-10,37 "
$$

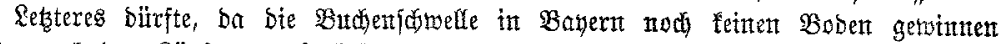

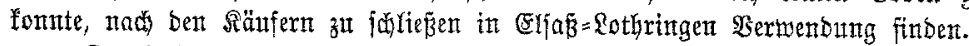

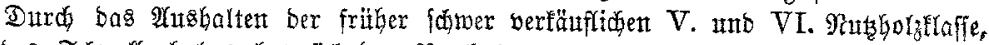

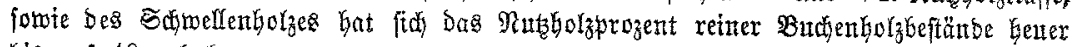
bis anf 40 gehoben. 